\title{
Construction of Green Power Development Evaluation System Based on TOPSIS Method
}

\author{
Zhuonan Li, Xue Tan, Yanming Jin and Qiuli Zhao ${ }^{{ }^{*}}$ \\ ${ }^{1}$ State Grid Energy Research Institute CO., LTD. Beijing, 102209, China
}

\begin{abstract}
In this paper, the green development evaluation system and method which is useful in power grid were studied and established, and the indicators that affect the green development process of the power grid were analyzed and classified. In order to reflect the comprehensive indicators of the assessment indicators and their impact on the whole society, the system also includes indirect indicators of power generation enterprises, government and social organizations as the main body of implementation, as the expansion of the power grid's green development. In the calculation period, the TOPSIS method was introduced for evaluating the results and indicators of different companies in two provinces. This research will provide an important reference for energy companies to improve the internal assessment methods for environmental protection and green development.
\end{abstract}

\section{Introduction}

Since the 1980s, many countries, international organizations, and relevant UN departments have begun to publish their own environmental reporting guidelines, which stipulate environmental performance evaluation standards[1]. At present, there are four common environmental performance evaluation standards in the world, namely the Canadian Institute of Chartered Accountants' Environmental Performance Report, the ISO 14031 evaluation standard[2], the eco-efficiency indicator proposed by the World Enterprise Sustainable Development Committee, and the Sustainability Reporting Guide. The proposed environmental performance indicators. However, the evaluation methods applicable to China's policy environment and energy development process are still in a state of vacancy. Therefore, it is necessary to establish a new indicator system to evaluate the green development status of provincial power grid companies.

\section{Indicator System Construction}

Considering China's special energy pattern, future energy companies will lead the green development path in the energy field. They need to consider from the aspects of strategic objectives, development methods, and industrial development: (1) Based on national conditions and the trend of world energy reform, determine the promotion of their own, industry and (2) Actively promote its own green development and transform the development mode of the power grid; (3) Actively promote the green development of industry and society, and promote the formation of a green power production chain, consumer chain and equipment chain. In this system, the indicators were divided into three groups.

\subsection{Green configuration}

The power grid is the hub connecting power generation and power consumption. It is also an important subject to promote energy transformation, boost energy supply and consumption revolution. Therefore, we must focus on the ability of the power grid as an energy resource optimization configuration platform and the operation effect. The green allocation index of the power grid examines the power generation capacity of the power grid for renewable energy generation, the power transmission capacity of the power grid across provinces, and the effectiveness of optimal dispatching.

\subsubsection{Renewable energy capacity ratio}

Renewable energy capacity rate $=$ renewable generator capacity / total capacity $\times 100 \%$

\subsubsection{Renewable energy abandonment rate}

It is also the basic requirement for green development to build a green grid platform to minimize the renewable energy abandonment rate and ensure the normal grid connection, delivery and consumption of clean energy power generation.

\subsubsection{Line loss rate}

Line loss rate $=$ total power consumption / total social power consumption $\times 100 \%$ 
Line loss is an important energy-saving and consumption-reducing indicator in the operation of the power grid. That is, the power lost in the power network accounts for the percentage of power supplied to the power network.

\subsubsection{Proportion of transmission capacity across provinces}

Trans-provincial line transmission capacity ratio $=$ crossregion line transmission capacity / annual maximum load of jurisdiction

\subsection{Green Service}

The green development of the power grid not only includes the transmission network and its power facilities as the basic orientation of ecological civilization[3], but also includes contributing to the efficiency and cleanliness of the consumption side, and providing green and high-quality services for the green development of the whole society.

\subsubsection{Smart meter penetration rate}

Smart meters have the advantages of more accurate measurement and remote transmission of information. Moreover, with the continuous development of component technology, smart meters can be continuously integrated to develop more functions. Users can make full use of the difference between peak and valley electricity prices to customize the electricity use plan, fully release the user side's participation in the demand side response.

\subsubsection{Comprehensive energy efficiency}

The comprehensive energy consumption is the ratio of the comprehensive energy consumption of the enterprise units to the total industrial output value in a certain period of time, and is a comprehensive indicator reflecting the high and low energy economic benefits of enterprises.

\subsubsection{Clean heating electricity consumption ratio}

Compared with fossil fuels, electric energy has the advantages of being clean, safe and convenient. The use of electric power for heating is of great significance for implementing the national energy strategy and promoting the clean development of energy terminal consumption.

\subsubsection{Distributed PV access capacity ratio}

Distributed PV access capacity ratio = distributed PV access capacity / total installed capacity

\subsection{Green Production}

The power transmission and transformation project can be regarded as the most direct reflection of the environmental impact of the power grid. The indicators set under this category are more scientifically disposed of with sound corporate operations, especially in the construction phase of power transmission and transformation projects.

\subsubsection{SF6 recycling rate}

SF6 recovery rate $=$ total SF6 recovery / SF6 release $\times$ $100 \%$

Sulfur hexafluoride has been used as one of the greenhouse gases affecting the global environment in the United Nations Framework Convention on Climate Change.

\subsubsection{Waste oil disposal rate}

Many electrical equipment are highly dependent on oil as a medium for circulating heat dissipation, whose maintenance and decommissioning involve the disposal of waste oil.

\subsubsection{Wastewater compliance rate}

The substation wastewater is essentially domestic sewage, and its treatment should be considered in combination with drainage characteristics and regional environmental conditions.

\subsubsection{Waste lead-acid battery recovery rate}

Waste lead-acid batteries contain a lot of heavy metals and are highly corrosive and toxic. If not handled properly, it is likely to cause environmental pollution problems.

\subsubsection{Treatment rate of power frequency electromagnetic field excess}

The power frequency electromagnetic field is an electromagnetic field generated by a $50-60 \mathrm{~Hz}$ power system. When the power frequency of the electrical equipment exceeds the standard, the health and life order of the surrounding residents will be affected.

\subsubsection{Noise exceeding standard rate}

Excessive noise has always been an important target for domestic and international power grids, and with the improvement of people's living standards and environmental awareness, the control of noise pollution has become more stringent. For the noise pollution caused by equipment aging and improper operation during the operation of the power grid, relevant measures must be taken. 


\section{Evaluation Method}

There are many comprehensive evaluation methods and TOPSIS method is introduced in this paper. The TOPSIS (Technique for Order Preference by Similarity to an Ideal Solution) method was first proposed by C.L.Hwang and K.Yoon in 1981, and is also known as the superior and inferior solution distance method. The TOPSIS method is a sorting method that approximates the ideal solution. This method only requires that each utility function has a monotonous increment. The basic principle is to sort by measuring the distance between the evaluation object and the optimal solution and the worst solution. If the evaluation object is closest to the optimal solution and farthest from the worst solution, it is the best; otherwise it is not optimal. The index values of the optimal solution reach the optimal value of each evaluation index[4,5].

The TOPSIS analysis method needs to have $\mathrm{m}$ targets (limited targets) and $\mathrm{n}$ attributes. The expert evaluates the $\mathrm{j}$-th attribute of the $\mathrm{i}$-th target to Xij, and the initial judgment matrix $\mathrm{V}$ is:

$$
V=\left[\begin{array}{ccccc}
x_{11} & \cdots & x_{1 j} & \cdots & x_{1 n} \\
\vdots & \ddots & & & x_{2 n} \\
x_{i 1} & & x_{i j} & & x_{i n} \\
\vdots & & & & \\
x_{m 1} & & & & x_{m n}
\end{array}\right]
$$

Since the dimensions of each indicator may be different, the decision matrix can be normalized as:

$$
V^{\prime}=\left[\begin{array}{ccccc}
x_{11}^{\prime} & \cdots & x_{1 j}^{\prime} & \cdots & x_{1 n}^{\prime} \\
\vdots & \ddots & & & x_{2 n}^{\prime} \\
x_{i 1}^{\prime} & & x_{i j}^{\prime} & & x_{i n}^{\prime} \\
\vdots & & & & \\
x_{m 1}^{\prime} & & & & x_{m n}^{\prime}
\end{array}\right]
$$

Here

$$
x_{i j}^{\prime}=\frac{x_{i j}}{\sum_{k=1}^{n} x_{i j}^{2}}
$$

According to the DELPHI method[6,7], the information weight matrix B of the expert group is obtained, and a weighted judgment matrix is formed.

$$
Z=V B=\left[\begin{array}{ccccc}
f_{11} & \cdots & f_{1 j} & \cdots & f_{1 n} \\
\vdots & \ddots & & & f_{2 n} \\
f_{i 1} & & f_{i j} & & f_{i n} \\
\vdots & & & & \\
f_{m 1} & & & & f_{m n}
\end{array}\right]
$$

According to the weighted judgment matrix, the positive and negative ideal solutions of the evaluation target are obtained. In this paper, the positive ideal solution is adopted. The formula is:

$$
f^{*}=\max f_{i j}, j=1,2,3 \ldots n
$$

Calculate the Euclidean distance between each target value and the ideal value. The solution formula is:

$$
S_{i}^{*}=\sum_{j=j}^{m}\left(f_{i j}-f_{j}^{*}\right)^{2}, j=1,2,3 \ldots n
$$

The targets are sorted according to the relative closeness, and the decision basis is formed to complete all calculations.

\begin{tabular}{|c|c|c|c|c|c|c|c|}
\hline & indicators & dimension & Weights & $\begin{array}{l}\text { Company A } \\
\text { (Value) }\end{array}$ & $\begin{array}{l}\text { Company B } \\
\text { (Value) }\end{array}$ & $\begin{array}{c}\text { Company A } \\
\text { (Standardized) }\end{array}$ & $\begin{array}{c}\text { Company B } \\
\text { (Standardized) }\end{array}$ \\
\hline \multirow{4}{*}{$\begin{array}{c}\text { Green } \\
\text { configur } \\
\text { ation }\end{array}$} & $\begin{array}{c}\text { Renewable energy capacity } \\
\text { ratio }\end{array}$ & $\%$ & 5 & 60.89 & 17.75 & 1 & 0.291509279 \\
\hline & $\begin{array}{l}\text { Renewable energy } \\
\text { abandonment rate }\end{array}$ & $\%$ & 3 & 2.16 & 7.42 & 1 & 0.291105121 \\
\hline & Line loss rate & $\%$ & 5 & 6.98 & 6.66 & 1 & 0.954154728 \\
\hline & $\begin{array}{l}\text { Transmission capacity } \\
\text { across provinces }\end{array}$ & $\%$ & 3 & 101 & 25.19 & 1 & 0.249405941 \\
\hline \multirow{4}{*}{$\begin{array}{c}\text { Green } \\
\text { Service }\end{array}$} & Smart meter penetration & $\%$ & 4 & 99.83 & 99.57 & 1 & 0.997395572 \\
\hline & Energy efficiency & $\begin{array}{c}\text { Coal } \\
\text { consumption } \\
\text { / GDP }\end{array}$ & 3 & 0.122 & 0.129 & 1 & 0.945736434 \\
\hline & $\begin{array}{l}\text { Clean heating electricity } \\
\text { consumption ratio }\end{array}$ & $\%$ & 4 & 4.41 & 4.68 & 0.942307692 & 1 \\
\hline & Distributed PV capacity & MW & 4 & 424 & 1481 & 0.286275863 & 1 \\
\hline
\end{tabular}

\section{Calculation and Results}

According to the data published in Power Industry Statistics Express and the data collected in different grid companies in each provinces.

Table 1. Formatting sections, subsections and subsubsections. 


\begin{tabular}{c|ccccccc}
\hline & SF6 recycling rate & $\%$ & 4 & 98.72 & 97.38 & 1 & 0.996555916 \\
& Waste oil disposal rate & $\%$ & 4 & 94.12 & 93.75 & 1 & 0.996150645 \\
$\begin{array}{c}\text { Green } \\
\text { Producti } \\
\text { on }\end{array}$ & Leastewater compliance & $\%$ & 4 & 98.6 & 96.1 & 1 & 0.984787018 \\
& $\begin{array}{c}\text { Electromagnetic excess } \\
\text { treatment }\end{array}$ & $\%$ & 4 & 96.72 & 95.52 & 1 & 0.98791636 \\
& Treatment of noise & $\%$ & 4 & 93.91 & 92.36 & 1 & 1 \\
\hline
\end{tabular}

The distance between company $\mathrm{A}$ and the ideal solution is: $\mathrm{S}_{1}=2.048$; And the distance between company $B$ and the ideal solution is: $S_{2}=5.731$. Company A has obvious advantages over Company $\mathrm{B}$, in all the indicators of the classification of Green configuration and Green Production, Company A is the ideal solution.

\section{Conclusion}

In this paper, a green development evaluation system of power grid based on TOPSIS method is completely established, which takes the functions of the grid, the promotion of green development on the power generation side and the extension of green development on the electricity side into account. In addition, the system demonstrates that it can relatively accurately assess the level of green development of each company's power grid. The evaluation system can be used for horizontal and vertical comparisons between power grid companies in different provinces, providing reference and guidance for the green development of power grids in various regions.

\section{Acknowledgments}

Support by Science and Technology Project of State Grid Corporation of China (SGNY0000NGJS1900127): Research on Strategic Planning Technology and Evaluation Method of Green Power Development Based on Thought of Ecological Civilization

\section{References}

1. Jin Huang. Research on Environmental Performance Evaluation Indicators in Different International Standards[J]. Standard Science, $2015,7$.

2. ISO14031: 2013 Environmental Management Environmental Performance Evaluation Guidelines.

3. Shao,Shuyue \& Liu, Wenzhe Tianjin University of Sport,China. Relationship between the ecological civilization and a nationwide fitness campaign[A]. Proceedings of 2008 International Convention on Science,Education and Medicine in Sport (Volume III) ,2008:1.

4. Juan M. S á nchez-Lozano,Jos é L. MeseguerValdenebro,Antonio Portoles. Assessment of Arc Welding Process Through the Combination of TOPSIS - AHP Methods with Fuzzy Logic[J]. Transactions of the Indian Institute of Metals,2017,70(4).

5. U. Pascal Onu,Quan Xie,Ling Xu. A Fuzzy TOPSIS model Framework for Ranking Sustainable Water Supply Alternatives[J]. Water Resources Management,2017,31(9).

6. Hugh Bowden. Athletes and oracles: the transformation of Olympia and Delphi in the eighth century $\mathrm{BC}[\mathrm{J}]$. The Journal of Hellenic Studies, 1992,112.

7. Thomas F. Madden. The Serpent Column of Delphi in Constantinople: Placement, Purposes, and Mutilations[J]. Byzantine and Modern Greek Studies, 1992,16. 